\title{
ESTIMATION OF THE EFFECTIVE OPERATIONAL MODE OF A CHILLER WITH COLD ACCUMULATOR FROM HEAT PIPES
}

\author{
Ikem Azorshubel Ikem ${ }^{1, *}$, M. I. Ibeh ${ }^{2}$, Ukwenya John ${ }^{3}$, \\ ${ }^{1}$ (Department of Mechanical Engineering, Faculty of Engineering, \\ Cross River University of Technology, Calabar-Nigeria) \\ azors9kee@yahoo.com \\ ${ }^{2}$ (Department of Mechanical Engineering, College of Engineering, \\ Michael Okpara University of Agriculture, Umudike-Nigeria) \\ matthewibeh@gmail.com \\ ${ }^{3}$ (Department of Mechanical Engineering, Benue State Polytechnic, Ugbokolo, Benue-Nigeria) \\ jornieukwenya@gmail.com \\ E-mail address: azors9kee@yahoo.com \\ *Corresponding author: Tel: +79615819083
}

\begin{abstract}
Accumulation of cold or heat is strongly associated with electric power availability, length of time and the cost of its supply. Accumulation of ice packs becomes a serious problem when electricity supply is irregular and worse when the voltage supplied is too low or barely sufficient to run the refrigerating equipment at full installation capacity. This irregular and insufficient electricity supply poses hindrance to industrialization of any society. This research is set up to investigate the possible ways of making use of automatic regulator (AR) to regulate available electricity supply in refrigerating equipment to accumulate ice packs during period of full electricity supply to be used when there is less electricity supply or none at all for considerable length of time.
\end{abstract}

Key words: Electric power, refrigerating equipment, industrialization, availability, cost.

\section{INTRODUCTION}

To smooth out the schedule of electricity consumption during the day, many countries introduced multi-rate tariffs for electricity during the day. Cold accumulators provide an even energy consumption and allows the reduction of the cooling capacity of the installed equipment. "Night" mode of accumulation of cold allows saving up to $25 \%$ of electric energy, in comparison with installations without an accumulation system [4].

The magnitude of "conventional" value of the refrigerant condensation temperature $t_{\mathrm{k}}$ is determined, in general, by the capacitor design and ambient parameters - temperature $t_{0 C}$ and relative air humidity $\varphi_{\text {o.c. }}$. In Russia $t_{\mathrm{k}}$ is defined for shell and tube condensers as $t_{\mathrm{k}}=t_{w .1}+7-8^{\circ} \mathrm{C}$, where $t_{w .1}$ is the water temperature at the condenser inlet.

The use of automatic regulator (AR) by cold accumulators to regulate the operation of refrigeration system makes it possible to lower the condensation temperature $t_{\mathrm{ki}}$ of the refrigerant with respect to the condensation temperature $t_{\mathrm{k}}$. In this case, the temperature $t_{\mathrm{ki}}$ is being regulated regardless of the change in $t_{0 . c}$ and $\varphi_{\mathrm{occ}}$, which ensures a uniform load and a decrease in compressor wear, a reduction in energy consumption, and a stable temperature operation in the refrigerator.

\subsection{System process description}

An example of the automatic regulator (AR) input for accumulating an amount $Q_{\mathrm{a}}$ of ice packs and subsequent lowering of $t_{\mathrm{ki}}$ is considered in Fig. 1; the basic diagram of the refrigeration unit with AR is shown in Fig. 2. 

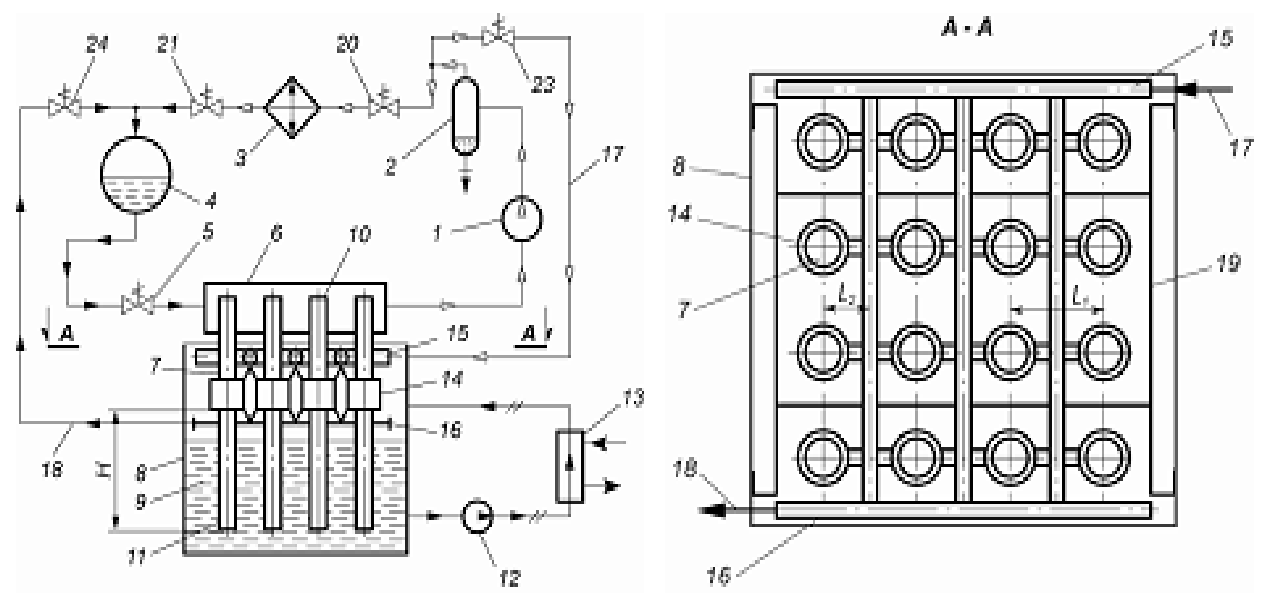

Figure 1 - Refrigeration unit with a cold accumulator from heat pipes

1- compressor; 2 - oil separator; 3 - capacitor; 4 - line receiver; 5 - throttle valve; 6 - evaporator; 7, 10, 11- heat pipes; 8 - accumulator tank; 9 - water; 12 - pump; 13 - heat exchanger plant; 14 - panel; 15 - steam manifold; 16 - liquid collector; 17 - steam pipe; 18 - liquid pipe; 19 - frame; 20, 21, 23, 24 - solenoid valves.

A refrigeration unit with a cold accumulator from heat pipes works as follows [5].

1.2 Ice Accumulation Process

In the process of ice accumulation, it is necessary estimate the quantity of ice that can freeze on the heat exchange surface, in order to do a theoretical analysis of the accumulator.

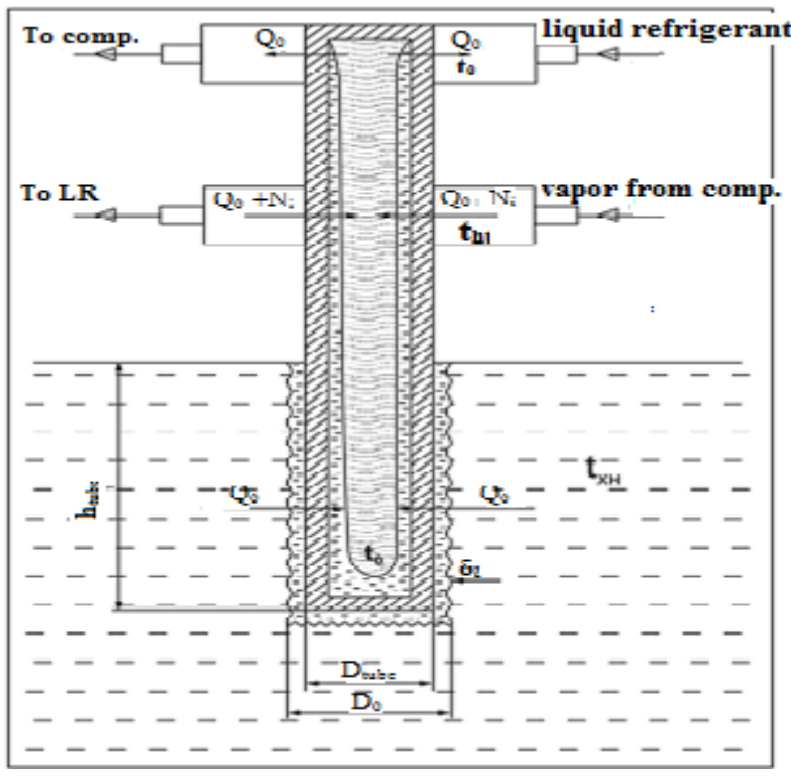

Figure 2: Heat pipe design calculation

Frozen ice in the accumulator periodically melts and discharged into the tank.

- The heat of freezing is determined by the formula

$q_{\text {freez }}=c_{w}\left(\mathrm{t}_{\mathrm{in}}-\mathrm{t}_{3}\right)+\gamma_{w}+c_{l}-\left(t_{3}-t_{l}\right)$,

Where the heat capacity of water,

$C_{w}$ - water heat capacity, $\mathrm{kJ} \mathrm{kg}^{-1} \mathrm{~K}$

$C_{l}$ - ice heat capacity, $\mathrm{kJ} \mathrm{kg}^{-1} \mathrm{~K}$;

$r_{w}$ - ice heat of formation, $\mathrm{kJ} \mathrm{kg}^{-1} \mathrm{~K}$;

$t_{\text {in }}$ - initial temperature of ice formation is ${ }^{0} \mathrm{C}$;

- The heat of defrosting is determined by the formula

$q_{\text {def }}=c_{l}\left(t_{\text {def }}-t_{l}\right)+\gamma_{0}$,

The calculation results are used to determine the time of freezing and the time of thawing. 
1.3 Freezing time

$\tau_{\text {freez }}=\frac{q_{z} \cdot \rho_{l}}{t_{z}+\left|t_{0}\right|} \cdot\left(\frac{\delta_{l}^{2}}{2 \cdot \lambda_{l}}+\frac{\delta_{\text {freez }}}{\alpha_{a}}\right)$

1.4 Thawing time

$\tau_{\text {def }}=\frac{q_{\text {def }} \cdot \rho_{l}}{t_{\text {def }}+\left|t_{\mathrm{ht}}\right|} \cdot\left(\frac{\delta_{\text {def }}^{2}}{2 \cdot \lambda_{w}}+\frac{\delta_{\text {freez }}}{\alpha_{a}}\right)$

where

$\rho_{l}$ - density of ice, $\mathrm{Kg} / \mathrm{m}^{3}$;

$\lambda_{l}-$ ice thermal conductivity, W/Mk;

$\lambda_{w}$ - water thermal conductivity, $\mathrm{W} / \mathrm{mk}$;

$\delta_{w}$ - pipe thickness, $\mathrm{m}$

$\alpha_{a}-$ coolant coefficient of heat transfer, $\mathrm{W} /\left(\mathrm{m}^{2} . \mathrm{K}\right)$

The mass $m_{\max }$, of frozen-ice produced in one cycle is determined by the formula

$m_{\text {max }}=\mathrm{N}_{\text {tube }} \cdot\left[\pi \cdot\left(\frac{D_{0}^{2}-D_{\text {tube }}^{2}}{4}\right) \cdot h_{\text {tube }}+\frac{\pi \cdot D_{0}^{2}}{4}\right] \cdot \rho_{l}$

where $\mathrm{N}_{\text {tube }}$ - number of tubes in the accumulator, packs;

$\mathrm{D}_{0}$ - frozen layer outer diameter, $\mathrm{m}$;

$D_{\text {tube }}$ - pipe diameter, $\mathrm{m}$;

$h_{\text {tube }}$ - height of the tube inserted in the solution, $\mathrm{m}$.

2 Number of freezing and thawing cycles during accumulation

$n_{\text {cycle }}=\frac{\tau_{\text {acc. }}}{\left(\tau_{\text {freez }}+\tau_{\text {def }}\right)}$

where $\tau_{\text {acc. }}-$ the "night time" of accumulation,

Adopted $\tau_{\text {acc. }}=8 \times 3600=28800 \mathrm{~s}$.

$m_{\text {acc. }}=\mathrm{m}_{\max } \cdot \mathrm{n}_{\text {cycle }}$,

1.5 Determination of discharge time of the accumulator

The mass of ice accumulated over night and later spent on production needs reducing the condensation temperature of the refrigerating plant.

Heat going to the accumulator discharge is according to figure 2

$Q=Q_{0}+Q_{K}=Q_{0}+\left(Q_{0}+N_{i}\right)$,

Where $Q$ - is the cooling capacity of installation, $\mathrm{kW}$;

$N_{i}$ - indicated power of the compressor, $\mathrm{kW}$.

$\tau_{\text {pap }}=\frac{2 \cdot\left(Q_{0}+N_{i}\right)}{m_{\text {acc }} \cdot \gamma_{l}}$

\subsection{Measuring Physical Quantities and Experimentation}

Measuring instrument used: Copper - constantan thermocouple of temperature range $0{ }^{0} \mathrm{C}$ to $+100{ }^{0} \mathrm{C}$ and sensitivity conversion coefficient of $41 \mu \mathrm{v} /{ }^{0} \mathrm{C}$ [2] with errors of $\pm(0.1-0.2){ }^{\circ} \mathrm{C}$, acceptable when testing heat exchangers [1]. Other simple temperature measuring device with a scale division of $0.1{ }^{\circ} \mathrm{C} 0$ is the mercury in glass laboratory thermometer.

Pressure gauge models (range of $0-2.5 \mathrm{MPa}$ with accuracy level 0.4 ) was used for pressure measurement.

Hot water counters with sensitivity threshold of $0.03 \mathrm{~m}^{3} / \mathrm{hr}$ with smallest scale interval value of $0.0002 \mathrm{~m}$ and limiting average integral of relative error of not more than $\pm 1.8 \%$ was used to measure the flow of coolant passing through the evaporator.

Airflow measurement through the condenser was carried out by multi-range manometer inclined tube, whose sensor uses a Pitot tube mounted in the center of the duct before the condenser. The coolant pressure drop $\Delta \mathrm{P}$ as it passes through the condenser was measured by taking the static pressure before and after the condenser [3].

The humidity in the experimental setup and the environment was measured by aspiration psychrometer, at a flow rate of $2.0 \mathrm{~m} / \mathrm{s}$.

Power consumed by the heater and the coolant cooling the condenser was measured by laboratory wattmeter of accuracy class of 0.5 


\section{$2.1 \quad$ Experimentation}

Compressor 1 sucks the refrigerant vapor from the evaporator and, when valve 20 is opened, it is pumped into the condenser 3 where the vapor condenses and, with the valve 21 open, the liquid refrigerant merges into the line receiver 4 . Through the throttle valve 5, liquid refrigerant enters the evaporator 6 where it vaporizes, cooling the upper parts 10 of the heat pipes 10 . The cycle in the refrigerant circuit is completed.

From the evaporator 6 is given to the refrigerant heat of condensation by the antifreeze working substance, which filled the heat pipe, and flows into the lower part 11 of the heat pipes 7 placed in the tank 8 , and is evaporated in the lower part 11. On the outer surfaces of the part 11 of the heat pipes 7 placed in the water, ice shells are accumulating, which are cold accumulators. The water in the tank is cooled to $0{ }^{\circ} \mathrm{C}$ and the cooled water from the tank 8 is taken by the pump 12 and fed to the cold consumer 13 where the cooling process takes place, it is cooled and then returns to the tank 8 . The cycle in the circulation loop of water as a coolant is completed.

When a layer of ice of maximum permissible thickness $\delta$ is created on the heat exchange surface of the lower part of the heat pipes, valve 23 is opened, valves 20 and 21 are closed, and the refrigerant vapor after the oil separator 2 is directed through the pipeline 17, the collectors 15 and cavities of the panels 14 . At the same time, when the heat of condensation of refrigerant vapor enters the hollow sections 14, the circulation of the antifreeze working fluid of the heat pipes 7 is reversed, (by "reversing" the flow direction of the antifreeze working medium inside the heat pipe), after which the lower part of the pipe 11 functions as a condenser for the antifreeze working fluid. At the same time, the heat of condensation of the refrigerant and the heat of condensation of the antifreeze working fluid ensures the attenuation of frozen ice from the outer surface of the lower part 11 of the heat-exchange tube 7 . The ice-freezing process is completed

The melted ice layers from the outer surface of the lower part 11 of the heat pipes 7 slide into the water filling the tank 8 without affecting the annulus, which allows free water access to the outer surface of the lower part 11 of the heat pipes 7 with subsequent freezing.

\subsection{Results and Discussion}

$$
\text { Table 1: } \mathrm{t}_{0} \quad=-5^{\circ} \mathrm{C} ; \quad t_{l}=-2{ }^{\circ} \mathrm{C} ; t_{h t}=25^{\circ} \mathrm{C} \text {. }
$$

\begin{tabular}{|l|lllllllll|}
\hline$\delta_{l}, m$ & & $\mathbf{0 , 0 0 5}$ & $\mathbf{0 , 0 1}$ & $\mathbf{0 , 0 1 5}$ & $\mathbf{0 , 0 2}$ & $\mathbf{0 , 0 2 5}$ & $\mathbf{0 , 0 3}$ & $\mathbf{0 , 0 3 5}$ & $\mathbf{0 , 0 4}$ \\
\hline $\begin{array}{l}\tau_{\text {freez }}, \\
s\end{array}$ & $R 134 a$ & 891,076 & $\begin{array}{l}2003,94 \\
6\end{array}$ & 3858,728 & 6455,423 & 9794,031 & 13874,55 & 18696,99 & 33 \\
\hline
\end{tabular}

Table 2:

$\mathrm{t}_{0} \quad=-5^{\circ} \mathrm{C} ; \quad t_{l} \quad=-2{ }^{\circ} \mathrm{C} ; t_{h t}=25^{\circ} \mathrm{C}$.

\begin{tabular}{|c|c|c|c|c|c|c|c|c|c|}
\hline \multicolumn{2}{|c|}{$\delta_{l}, m$} & 0,005 & 0,01 & 0,015 & 0,02 & 0,025 & 0,03 & 0,035 & 0,04 \\
\hline \multicolumn{2}{|c|}{$m_{\max }, \mathrm{kg}$} & 4,217 & 9,908 & 17,108 & 25,851 & 36,172 & 48,106 & 61,686 & 76,949 \\
\hline$n_{\text {cycle }}$ & $R 134 a$ & 29,038 & 13,684 & 7,274 & 4,393 & 2,911 & 2,061 & 1,532 & 1,182 \\
\hline$m_{\mathrm{a} c c .}$ & $R 134 a$ & 122,450 & 135,579 & 124,438 & 113,559 & 105,284 & 99,136 & 94,510 & 90,966 \\
\hline
\end{tabular}

Table 3: $\quad \mathrm{t}_{0}=-5^{\circ} \mathrm{C} ; t_{l} \quad=-2{ }^{\circ} \mathrm{C} ; t_{h t}=35^{\circ} \mathrm{C}$.

\begin{tabular}{|c|ccccccccc|}
\hline \multicolumn{2}{|c}{$\delta_{l}, m$} & $\mathbf{0 , 0 0 5}$ & $\mathbf{0 , 0 1}$ & $\mathbf{0 , 0 1 5}$ & $\mathbf{0 , 0 2}$ & $\mathbf{0 , 0 2 5}$ & $\mathbf{0 , 0 3}$ & $\mathbf{0 , 0 3 5}$ & $\mathbf{0 , 0 4}$ \\
\hline \multicolumn{2}{|c|}{$m_{\text {max }}, k g$} & 4,217 & 9,908 & 17,108 & 25,851 & 36,172 & 48,106 & 61,686 & 76,949 \\
\cline { 1 - 6 }$n_{\text {cycle }}$ & $R 134 a$ & 29,906 & 13,874 & 7,327 & 4,412 & 2,919 & 2,065 & 1,534 & 1,184 \\
\cline { 1 - 5 }$m_{\text {acc. }}$ & $R 134 a$ & 126,109 & 137,459 & 125,349 & 114,060 & 105,591 & 99,340 & 94,655 & 91,074 \\
\hline
\end{tabular}

Table 4:

$\mathrm{t}_{0}=-5{ }^{\circ} \mathrm{C} ; t_{l}=-2{ }^{\circ} \mathrm{C} ; t_{h t}=45^{\circ} \mathrm{C}$.

\begin{tabular}{|c|c|c|c|c|c|c|c|c|c|}
\hline \multicolumn{2}{|c|}{$\delta_{l}, m$} & 0,005 & 0,01 & 0,015 & 0,02 & 0,025 & 0,03 & 0,035 & 0,04 \\
\hline \multicolumn{2}{|c|}{$m_{\max }, k g$} & 4,217 & 9,908 & 17,108 & 25,851 & 36,172 & 48,106 & 61,686 & 76,949 \\
\hline$n_{\text {cycle }}$ & $R 134 a$ & 30,411 & 13,981 & 7,357 & 4,423 & 2,924 & 2,067 & 1,536 & 1,184 \\
\hline$m_{\mathrm{a} c c .}$ & $R 134 a$ & 128,238 & 138,526 & 125,861 & 114,340 & 105,763 & 99,454 & 94,735 & 91,133 \\
\hline
\end{tabular}


where $t_{0} ; t_{l}: t_{h t}$; are refrigerant boiling point; ice temperature; and heating temperature during defrosting respectively.

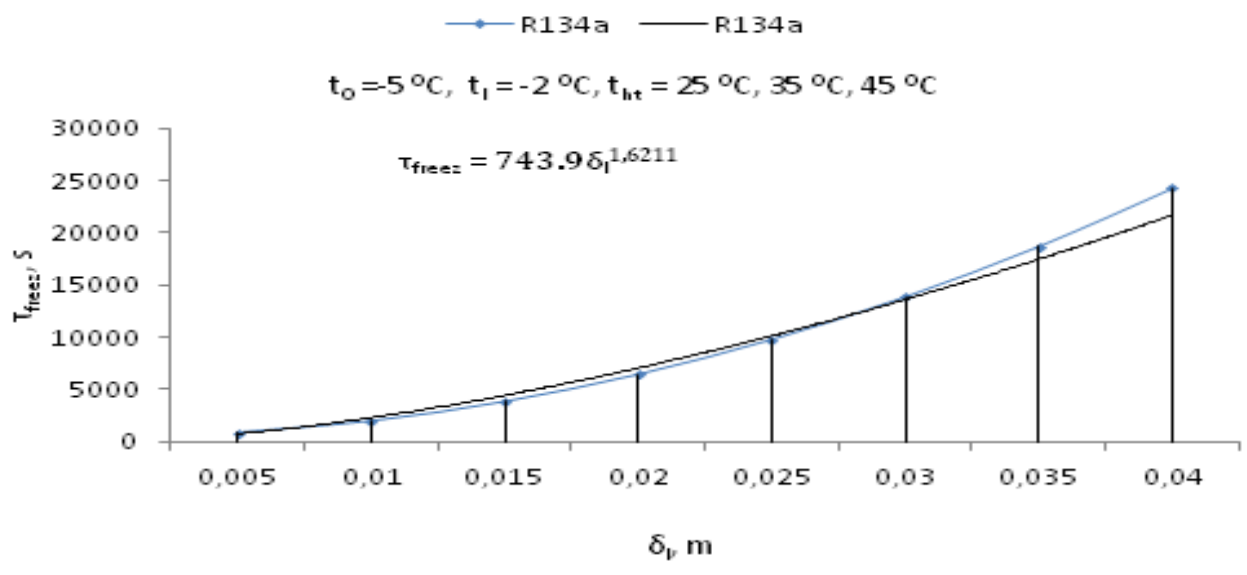

Graph 1: charging time of freezing, $\left(\tau_{\text {freez }}, \mathrm{s}\right)$ depending on the ice thickness.

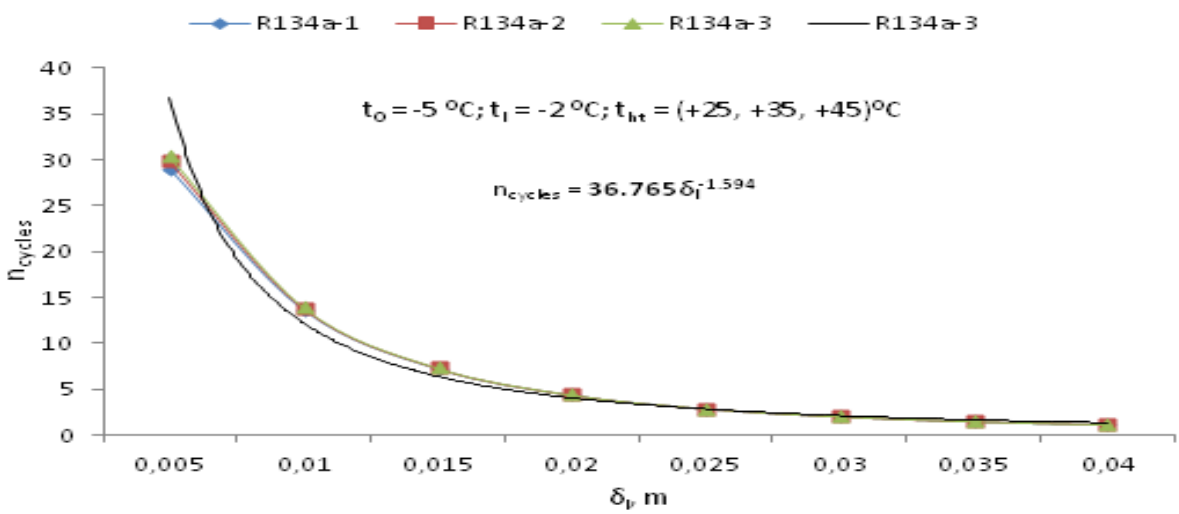

Graph 2: Number of charging cycles ( $\left.\mathrm{n}_{\text {cycles }}\right)$ depending on the ice thickness.

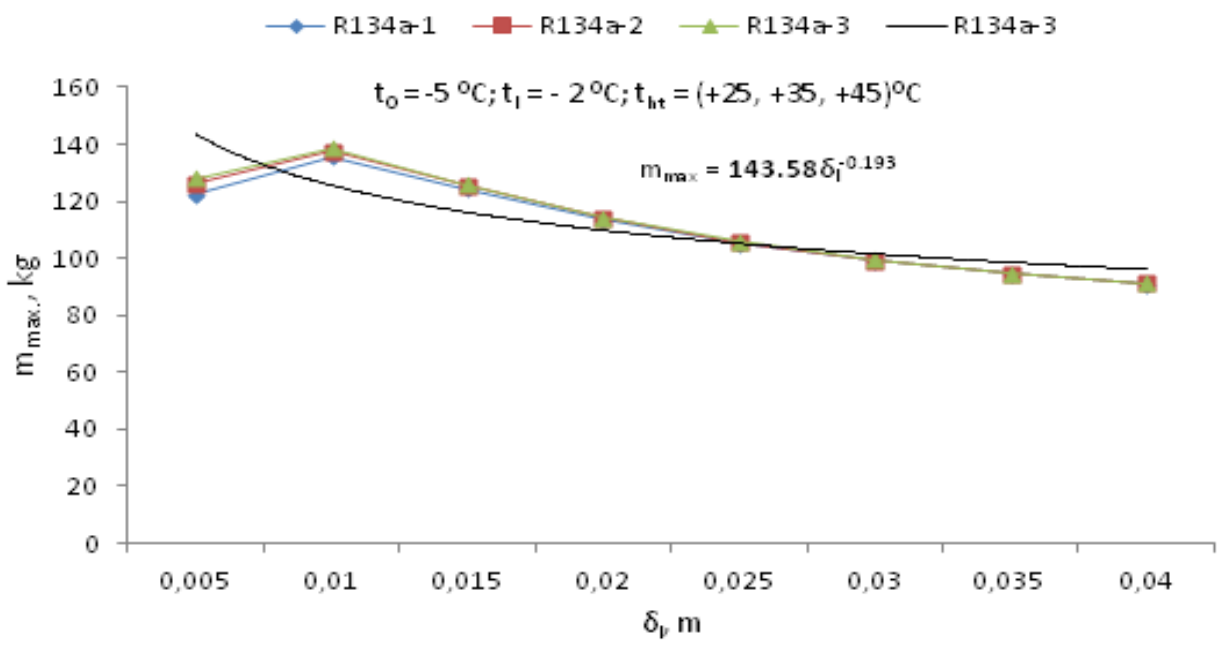

Graph 3: Mass of freezing ice $\left(\mathrm{m}_{\mathrm{max}}, \mathrm{kg}\right)$ depending on its thickness.

An increase in the thickness of the ice during the charging of the accumulator to $0.01 \mathrm{~m}$ results in an increase in the charging time and decrease in the mass of ice accumulated over a given time (graph1) based on table 1

Total number of charging cycles during the freezing time of accumulation is shown in graph 2 . The thickness decreases with increase in the number of cycles until a maximum point where no matter the number of cycles, ice is no longer formed on the heat exchange surface. This graph is based on tables (2 to 4).

The maximum mass of ice during the accumulation time is obtained when the ice is frozen to a thickness of up to $8 \mathrm{~mm}$ (graph 3 ) based on tables (2 to 4 ). 


\subsection{Conclusion}

1. It takes about 6 hrs 45 minutes to freeze maximum weight of ice based on the capacity this refrigerating plant.

2. The thawing time of frozen ice depends on the heating temperature, $t_{h t}$.

3. The use automatic regulator helps in makes it possible to lower the condensation temperature $t_{\mathrm{ki}}$ of the refrigerant with respect to the condensation temperature $t_{\mathrm{k}}$.

\section{References}

[1] ASHRAE (2009). Fundamental hand book. Atlanta, Georgia, USA: American Society of Heating, Refrigerating and Air Conditioning Engineers.

[2] Avnel B. K. A study of the coefficients of heat and mass transfer of a longitudinally streamlined plate with inebriation. - Refrigeration, 1968 , no. 12 , pp. 13-18;

[3] А. В. Быкова.-Эксплуатация холодильников. Справочник. Под ред.М.:Пищевая промышленность, 1977. - 207 с.

[4] Шляховецкий В. М, Холодильная техника в условиях тропиков. - Краснодар /изд. КПИ, 1981. - 69с.

[5] Шляховецький В. М., Хамие Х. Н. Холодильная установка с аккумулятором холода из тепловых труб. Патент РФ., Пат.№ 2190813 Россия, МКЙ С1 7F 25B 7/00, F28 D15/02 № 2001105728.06; Заявл.28.02.2001, опубл. 10.10ю2002г., Бюл. № 28.

\section{Nomeclature}

\begin{tabular}{|c|c|}
\hline$\varphi_{o c}-$ Air humidity, & $\rho_{l}-$ Density of ice, $\left[\mathrm{kg} / \mathrm{m}^{3}\right]$ \\
\hline$t_{o . c}-$ Ambient temperature, $\left[{ }^{0} \mathrm{C}\right]$ & $\lambda_{l}$ - Ice thermal conductivity, $[\mathrm{W} / \mathrm{mk}]$ \\
\hline$t_{k}$ - Refrigerant condensation temperature, $\left[{ }^{0} \mathrm{C}\right]$ & $\lambda_{w}-$ Water thermal conductivity, $[\mathrm{W} / \mathrm{mk}]$ \\
\hline$t_{w}-$ Temperature of water, $\left[{ }^{0} \mathrm{C}\right]$ & $\delta_{w}-$ Thickness of tube, $[\mathrm{m}]$ \\
\hline$t_{\text {in }}$ - Initial temperature of ice formation, $\left[{ }^{0} \mathrm{C}\right]$ & $\alpha_{w}$ - Coolant coeff. of heat transfer, [W/m $\left.\mathrm{m}^{2} \mathrm{~K}\right]$ \\
\hline AR - Automatic regulator & $m_{m s x}-$ Mass of frozen ice, $[\mathrm{kg}]$ \\
\hline$Q_{a}$ - Quantity of ice formed, $[\mathrm{kg}]$ & $N_{\text {tube }}-$ Number of tubes, $[\mathrm{pcs}]$ \\
\hline$C_{w}-$ Heat capacity of water, $[\mathrm{kJ} / \mathrm{kgK}]$ & $D_{\text {tube }}-$ Internal diameter of tube, $[\mathrm{m}]$ \\
\hline$C_{I}-$ Heat of ice formation, $[\mathrm{kJ} / \mathrm{kgK}]$ & $D_{0}-$ Outer diameter of tube, $[\mathrm{m}]$ \\
\hline$r_{0}-$ Ice heat of formation, $[\mathrm{kJ} / \mathrm{kgK}]$ & $h_{\text {tube }}$ - Height of tube in solution, [m] \\
\hline$\tau_{\text {freez }}-$ freezing time of ice, $[\mathrm{s}]$ & $n_{\text {cycle }}$ - Number of cycles of ice accumulation \\
\hline$\tau_{d e f}$ - defrosting time of ice, $[\mathrm{s}]$ & $\tau_{a c c}-$ Adopted time, $[\mathrm{s}]$ \\
\hline$q_{\text {freez }}$ - Freezing heat of ice, $[\mathrm{KJ}]$ & Q - Cooling capacity of installation, $[\mathrm{kW}]$ \\
\hline$q_{d e f}$ - Defrosting heat of ice, $[\mathrm{kJ}]$ & $N_{\text {tube }}$-Indicated power of compressor, [kW] \\
\hline$\Delta p-$ Pressure drop, $[\mathrm{mPa}]$ & \\
\hline
\end{tabular}

